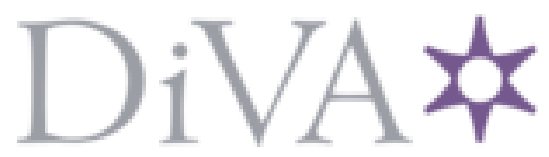

http://www.diva-portal.org

This is the published version of a paper published in Ecological Monographs.

Citation for the original published paper (version of record):

Merritt, D., Nilsson, C., Jansson, R. (2010)

Consequences of propagule dispersal and river fragmentation for riparian plant community diversity and turnover.

Ecological Monographs, 80(4): 609-626

http://dx.doi.org/10.1890/09-1533.1

Access to the published version may require subscription.

N.B. When citing this work, cite the original published paper.

Permanent link to this version:

http://urn.kb.se/resolve?urn=urn:nbn:se:umu:diva-37059 


\title{
Consequences of propagule dispersal and river fragmentation for riparian plant community diversity and turnover
}

\author{
David M. Merritt, ${ }^{1,2,4}$ Christer Nilsson, ${ }^{3}$ and Roland Jansson ${ }^{3}$ \\ ${ }^{1}$ National Watershed, Fish, Wildlife, Air, and Rare Plants, U.S. Forest Service, Natural Resource Research Center, \\ Fort Collins, Colorado 80526 USA \\ ${ }^{2}$ Natural Resource Ecology Laboratory, Colorado State University, Fort Collins, Colorado 80523 USA \\ ${ }^{3}$ Landscape Ecology Group, Department of Ecology and Environmental Science, Umeå University, SE-901 87 Umeå, Sweden
}

\begin{abstract}
The spatial distribution and temporal availability of propagules fundamentally constrain plant community development. This study experimentally tested several hypotheses about the relative roles of wind and water dispersal in colonization and development of riparian communities along rivers. Through controlling the source of propagules (dispersed by wind, water, or both) reaching newly created, bare river margin sites, we isolated the relative roles of dispersal and other factors in plant community development over five years. Replicated treatments were established at 12 sites spanning $400 \mathrm{~km}$ along two adjacent rivers in northern Sweden, one fragmented by a series of dams, the other free-flowing. Bare river margins receiving only water-dispersed propagules had significantly higher species richness compared to plots receiving only wind-dispersed propagules during the initial two years of colonization. Species richness increased annually throughout the study along tranquil and turbulent reaches of the free-flowing river but reached an asymptote at comparatively low richness after a single year on the impounded river. Propagule source strongly influenced species richness during the initial establishment along both rivers, with richness being significantly higher in plots receiving water-dispersed seeds. This strong treatment effect continued to be important through time along the regulated river but diminished in importance along the free-flowing river where other factors such as soil moisture, light availability, and exposure of sites to fluvial disturbance overshadowed the influence of dispersal pathway in mediating species richness. This suggests that hydrochory (plant dispersal by water) may be more important for maintenance of diversity in regulated systems where long-distance dispersal is absent or negligible, but that the rich local propagule source along free-flowing rivers supports high species richness. The number of unique species was higher in water-dispersal plots along both the regulated and free-flowing rivers. This result suggests that hydrochory may contribute to temporal variability of sites, may enhance richness over time, and may have an important role in meta-population and meta-community dynamics of plant communities through long-distance (and local) dispersal and chance colonization. Our findings provide experimental evidence that water dispersal of plant propagules influences colonization dynamics and is important for long-term community development in riparian zones.
\end{abstract}

Key words: fragmentation; hydrochory; northern Sweden; riparian plants; rivers; species richness; species turnover; water dispersal; wind dispersal.

\section{INTRODUCTION}

Ecologists have long sought to understand the relative importance of the various processes that influence species diversity at different scales. There has been a temptation to develop either/or hypotheses that pit processes working at one scale against processes operating at another (Huston 1999, Srivastava 1999). For example, it is debated whether local-scale processes such as niche differentiation, competitive exclusion, and localized disturbance ultimately limit species diversity or

Manuscript received 24 August 2009; revised 16 February 2010; accepted 23 February 2010. Corresponding Editor: M. W. Doyle.

${ }^{4}$ E-mail: dmmerritt@fs.fed.us whether diversity is most influenced by regional-scale factors such as long-distance dispersal and speciation (Ricklefs 1987, Holyoak et al. 2005). In fact, diversity at a particular spatial scale is constrained by a hierarchy of processes rather than by exclusively local or regional ones (Ricklefs 1987, 2004). It has been suggested that competition for niche space may limit the number of species that can coexist locally in "species-saturated communities," whereas richness in unsaturated communities tends to track richness of regional species pools (Srivastava 1999, Starzomski et al. 2008). However, there is little evidence that saturated communities exist in natural systems, particularly in systems that are regularly disturbed (e.g., riparian ecosystems; Levine 2000, Xiong et al. 2003). A fundamental constraint on 
local species richness is the number of species potentially available for colonization from the regional species pool (Zobel 1997). Thus, the number of species available at the local scale is mediated by connectivity between source populations and sites through dispersal and migration; the more permeable the landscape, the freer the flow of propagules and the more closely local communities may track regional species pools. Rivers are ideal systems for examining the relative roles of such processes because rivers are biophysically complex, they have seasonally variable flow and disturbance regimes, they serve as corridors that connect otherwise disconnected landscapes, and riparian and aquatic communities experience regular localized extinction and colonization. Understanding the individual and combined importance of these processes requires experimentation at the landscape scale, yet there are few large-scale and long-term studies of plant dispersal. One of the objectives of the current work was to compare and contrast establishment and plant community development along adjacent free-flowing (connected) and regulated (fragmented) rivers in northern Sweden at a catchment scale and over five growing seasons. To discern the role of dispersal, we controlled the sources of seeds reaching open patches along river margins.

Along rivers, physical and chemical processes (e.g., flooding, anoxia, burial, and scour) may cause recurrent local extinctions in riparian plant communities and create new sites for colonization. The magnitude of flood-driven disturbance and the time between such events vary over the course of a season and from year to year, enabling newly created sites to be recolonized. Local extinction may be offset by recolonization from neighboring, extant vegetation (e.g., vegetative growth) or from propagules derived locally or from elsewhere (Kalliola et al. 1991, Johansson et al. 1996). While driving disturbance processes, variable hydrologic regimes and fluvial processes also create and maintain a complex physical environment of substrates, microtopographic relief, hydrologic gradients, and biochemical processes along river margins. Collectively, these processes provide establishment opportunities to a range of species. Such environmental heterogeneity and disturbance influence all stages of plant establishment: dispersal, colonization, and population growth (With 2002), yet the spatial distribution and temporal availability of propagules may fundamentally constrain establishment and community development.

River margins are depositories of tremendous numbers of propagules (Nilsson and Grelsson 1990, Andersson and Nilsson 2002, Vogt et al. 2006). Some of these are from local sources ( $<100 \mathrm{~m}$; Levine 2003) and others are transported far (e.g., hundreds of kilometers) by water (Andersson et al. 2000b, Boedeltje et al. 2003). As a consequence, rivers are unique landscape elements in that they biologically (mainly through hydrochory) connect otherwise disconnected meta-populations or meta-communities (Boudell and Stromberg 2008), ac- celerate colonization, and possibly enhance potential diversity through transporting propagules long distances from throughout a catchment (Nilsson et al. 1991b, 1994, Andersson et al. 2000b). Water dispersal is a secondary dispersal mechanism for many riparian species, but deposition in water can enhance a propagule's chances of reaching a safe site for establishment through dispersing farther from parent plants (decreasing intraspecific competition; i.e., Janzen-Connell effect; Bever 2003). Water dispersal may extend the period over which seeds disperse ("effective dispersal"), and propagules can benefit from directed dispersal if watertransported seeds are deposited nonrandomly in sites more conducive to germination and survival (Merritt and Wohl 2002).

Dams alter the delivery of seeds to channel margins and floodplains through governing the timing and magnitude of flows, in some cases decoupling the necessary site conditions for germination and survival with the availability of propagules or other life-history requirements (Mahoney and Rood 1998, Jansson et al. 2000b, Merritt and Wohl 2006). Dams are also barriers to the movement of propagules along river corridors, trapping $75-95 \%$ of propagules and reducing the propagule species diversity in rivers along reaches downstream of dams (Andersson et al. 2000b, Jansson et al. 2005). Dams obstruct dispersal of seeds from regional seed sources upstream, which may reduce potential richness of downstream plant communities (Merritt and Wohl 2006, Brown and Chenoweth 2008). Jansson et al. (2000b) concluded that plant communities within impoundments were isolated (and compositionally distinct) from plant communities in impoundments upstream and downstream. Disconnection of riparian zones from their river channels may also affect plant colonization. Leyer (2006) found that disconnected floodplains along the Elbe River in Germany had fewer species-rich plant communities compared to those that remained connected with the river channel. This result is supported by Jansson et al. (2005), who found that recently established plant communities along river margins receiving hydrochores had $36-58 \%$ more species than adjacent communities colonized only by wind- and animal-dispersed seeds, and these results did not differ between free-flowing and dam-fragmented rivers.

Isolating the relative importance of altered physical processes caused by dams (e.g., hydrology, sediment transport, fluvial processes) and the barriers to plant dispersal in reducing biodiversity of river margin vegetation along regulated rivers requires field experiments that account for the hierarchy of controls on riparian communities. The aim of the current study was to better understand the relative roles of site-level environmental factors (e.g., resources and disturbance intensity), fragmentation, and local vs. regional propagule supply in the establishment, richness, community development, and species turnover in riparian plant communities along two adjacent boreal rivers: one 
fragmented by multiple dams and the other free-flowing. Designing the experiment so that each individual site was a complete replicated experiment enabled us to compare within- and between-site variability over five years of community establishment and development. A conceptual model of the differences between local and regional propagule pools in free-flowing and regulated rivers is outlined in Fig. 1. We hypothesize a reduction in the potential regional propagule pool following regulation of a river, leading us to four hypotheses about how the characteristics of riparian vegetation are governed in dam-fragmented and longitudinally connected systems:

1) If the size of the propagule pool decreases as a result of dams obstructing hydrochory, richness of local communities should also decrease. Thus, the number of species colonizing new sites along a regulated river will be lower than along a free-flowing river.

2) Local-scale (plot) and reach-scale species richness should be higher in communities receiving propagules from regional propagule pools. When such access is reduced or absent, community richness will reflect local species pools.

3) Numerous experimental and observational studies suggest that local plant communities are seed-limited (Burke and Grime 1996, Srivastava 1999, Turnbull et al. 2000). If seed-limited, the species composition of communities may reflect the composition of the seeds arriving, assuming that life-history processes occurring between seed arrival and the progression to adult plants do not overwhelm the template laid out by dispersal. Plots colonized by local seed sources will then be more similar in composition to adjacent standing vegetation than will plots colonized by seeds from regional propagule pools.

4) Interannual species turnover will be higher in areas receiving seeds from regional species pools (facilitating colonization) and those that are more fluvially active (causing mortality of seedlings and localized extinctions by physically removing or burying individuals). Colonization will be higher in habitats where seeds are derived from regional propagule pools, whereas extinction will be proportional to the frequency, duration, and intensity of fluvial disturbance.

\section{Methods \\ Study sites}

The adjacent Vindel and Ume Rivers originate at the drainage divide between Sweden and Norway in the Scandes Mountains ( $>1600 \mathrm{~m}$ above mean sea level). The seventh-order rivers flow through a formerly glaciated landscape above $220 \mathrm{~m}$ above sea level at which elevation the geology transits from glacially deposited morainic substrates to deltaic valley deposits. This transition is associated with the former shoreline of the Ancylus Lake, a freshwater precursor of the Baltic Sea following the last glacial episode. The Ume and Vindel Rivers flow through parallel valleys with similar

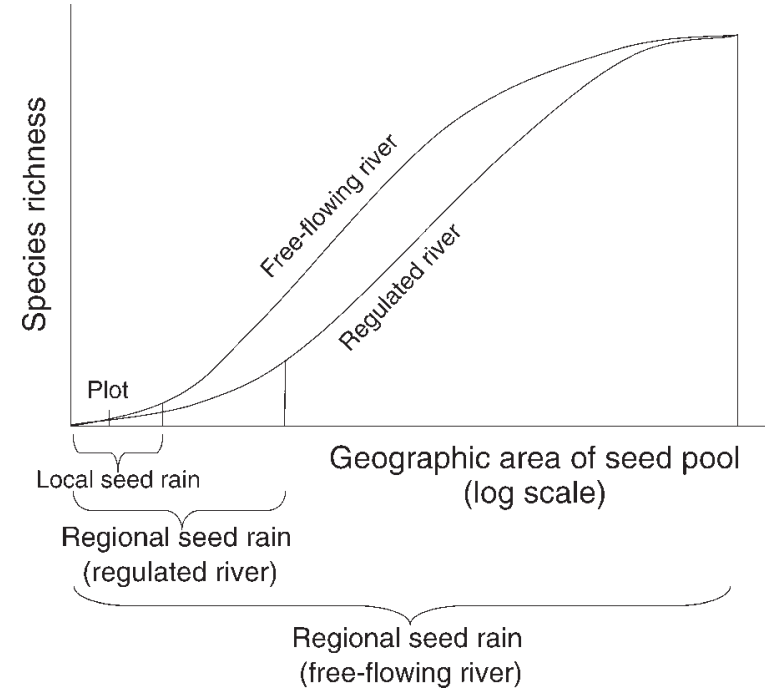

FIG. 1. Conceptual model showing hypothesized species accumulation curves for an entire free-flowing river and an impounded river. Vegetation at a site along a free-flowing river can potentially exhibit species from the entire catchment upstream through the receipt of propagules delivered to channels from throughout the upstream network. Along the regulated river, the regional species pool is reset at each impoundment and contains propagules only from the contributing area (and tributaries) downstream from the nearest dam.

geology, climate, and historic flow regimes and plant communities; however, the Vindel River is free-flowing from the mountains to the coastal plain and the main channel of the Ume River is regulated by 16 dams along its course (Fig. 2). These rivers have been examined in a number of paired catchment studies over past decades (Nilsson et al. 1991a, Andersson et al. 2000a, Jansson et al. 2005) and form a unique pairing for the study of dispersal.

The Vindel River experiences considerable water-level fluctuations with annual, snowmelt-driven peak flows averaging $911 \mathrm{~m}^{3} / \mathrm{s}$ in its lower reaches (typically occurring in mid-May to mid-June) and low flows averaging $31 \mathrm{~m}^{3} / \mathrm{s}$ (SMHI 1979). River margin vegetation along the Vindel River is vertically zoned, from upland forest communities (Picea abies, Pinus sylvestris, and Vaccinium spp.) furthest from the river to riparian forest communities (Alnus incana and Populus tremula), shrub vegetation dominated by Salix spp., and herbaceous communities dominated by graminoids nearest the active channel. Flooding occurs annually in spring and occasionally in summer during frontal rainstorms. The riparian shrub-forest transition zone is seasonally inundated and the riparian forest is flooded every other year on average. The Vindel River is morphologically complex, its longitudinal profile is stepped, with lowgradient, low-energy "tranquil" reaches occurring upstream and downstream from steep-gradient, highenergy "turbulent" reaches (Nilsson et al. 2002, Renöfält et al. 2007). 


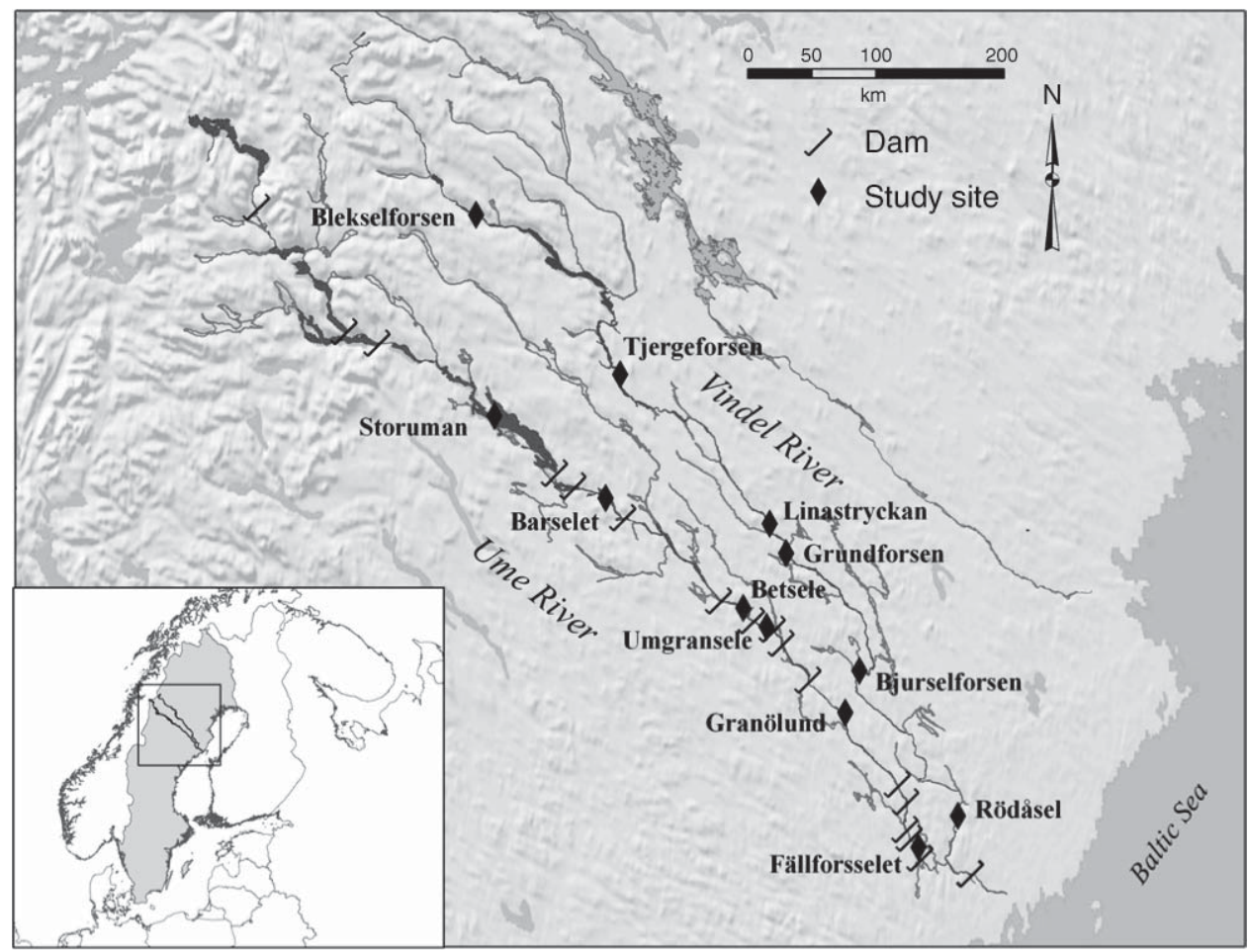

FIG. 2. Map of impounded Ume and free-flowing Vindel Rivers indicating locations of the 12 study sites (solid diamond symbols). The adjacent Ume and Vindel Rivers originate at the drainage divide between Sweden and Norway in the Scandes Mountains. The Ume River has 16 dams and reservoirs on its main channel from the mountains to the coast, and the Vindel River remains free-flowing. Each study site on the Vindel River is composed of paired turbulent and tranquil reaches. Each reach type at each site is composed of a fully replicated and controlled experiment with four replicate blocks, each containing a wind dispersal treatment, a water dispersal treatment, a wind and water dispersal treatment, and an unmanipulated control.

Reservoir water levels along the Ume River are determined primarily by hydroelectric power demands. Reservoir margin vegetation along the Ume River lacks distinct zonation and typically consists of boreal forest dominants (Picea abies and Pinus sylvestris) and annual and amphibious species along a narrow band of frequently flooded shorelines. Very few reaches of unflooded pre-regulation riparian vegetation remain along the Ume River, as much of the former channel is submerged under a number of reservoirs (Fig. 2). Reservoir shorelines along the Ume River are primarily sand and gravel and experience wave erosion and ice scour related to water-level fluctuations but lack fluvial processes.

\section{Experimental design}

To understand the role of local vs. regional seed sources in colonization and community development over five years (2000-2004), we cleared and "sterilized" soils in plots along river margins and then controlled the source of propagules (either water- or wind-dispersed propagules and a combination). Six sites were established along each of the two rivers at paired elevations with 60-m elevation intervals, covering a total distance of $>400 \mathrm{~km}$ from the Scandes Mountains to the Baltic coastal plain in June 2000 (Fig. 2). Study sites along the
Ume River were established along reservoir margins because the Ume River consists of nearly continuous run-of-river impoundments along its length from the mountains to the coast. Both tranquil (low-gradient, slow-flowing glides) and turbulent (high-gradient rapids) reaches of the Vindel River were sampled (Nilsson et al. 2002). Treatment blocks, each containing the three treatments (receiving wind-, water-, or wind- and waterdispersed propagules) and a control plot (unaltered vegetation), were randomly located along $200 \mathrm{~m}$ long transects (parallel to the river) along reservoir margins along the Ume River and along tranquil and turbulent reaches of the Vindel River. There were eight blocks of treated plots per site in the Vindel River and four blocks per site in the Ume River. Plots were all located at similar elevations above mean water level on both rivers, equivalent to the seasonally flooded shrub-tree transition zone on the Vindel River (Fig. 3). Zonation is very distinctive along the Vindel River, and this reference elevation was selected specifically because it would provide uniformity in hydrologic and hydraulic conditions and the influence of biotic factors (e.g., shading). Along the Ume River, the plots were placed above the level reached by daily and weekly water-level fluctuations to avoid destruction of the plots, especially by ice disturbance during winters (Jansson et al. 2005). 


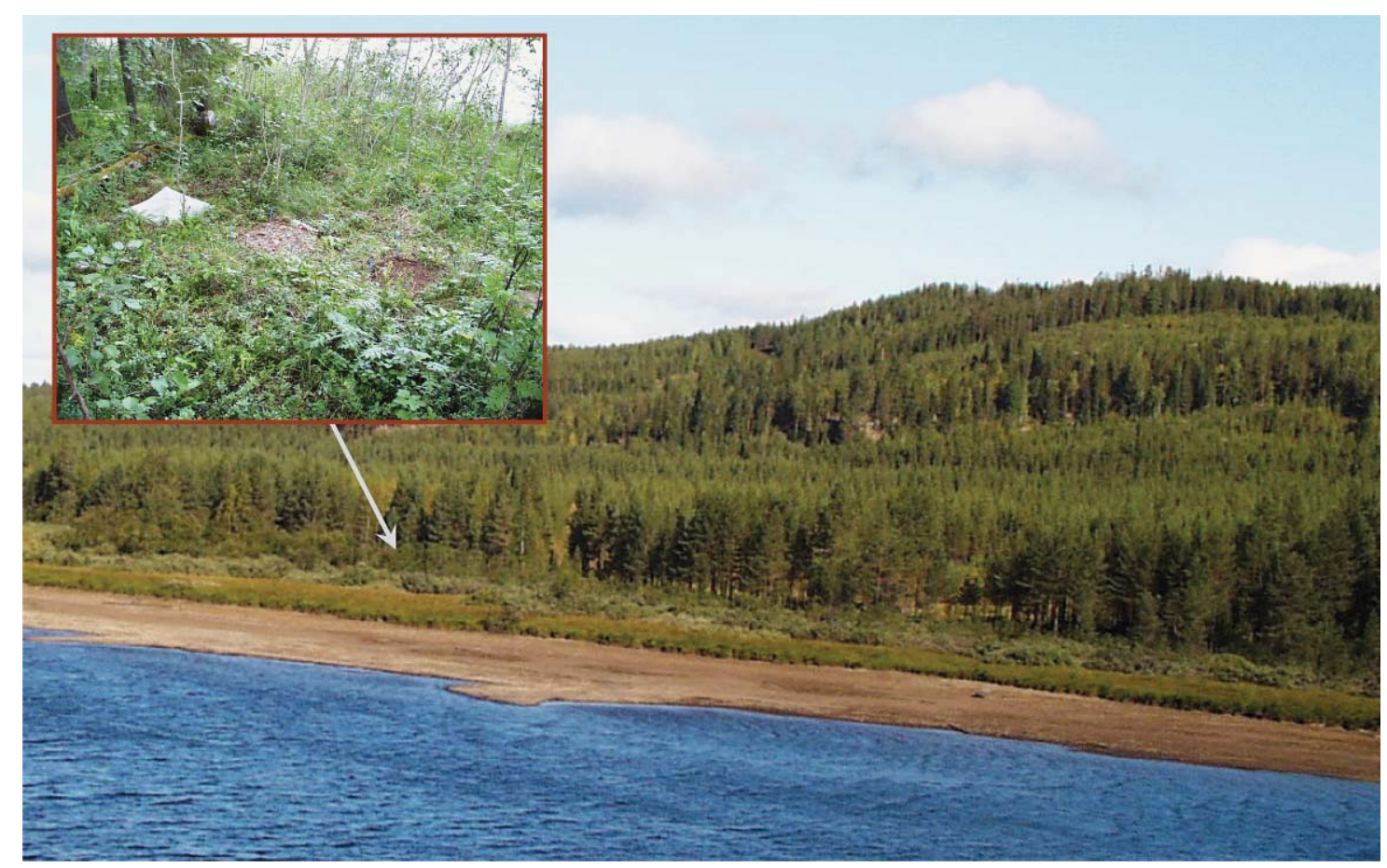

FIG. 3. Plant zonation along a river margin on the free-flowing Vindel River showing the transition from active river channel, herbaceous vegetation, shrub zone, and riparian forest to upland forest. Experimental plots $\left(0.25 \mathrm{~m}^{2}\right.$; inset) were established at the same reference elevation in the shrub-tree transition zone. This zone is seasonally flooded and receives river-transported drift annually.

Experimental plots $\left(0.25 \mathrm{~m}^{2}\right)$ were cleared of all vegetation by removing a $20 \mathrm{~cm}$ deep soil block and replacing it with fine, rinsed sand. Fine sand was gathered in the field from fresh fluvial deposits or submerged surfaces. Sand was submerged in a container, agitated to separate organic and mineral material, and floating material poured off. This process was repeated several times. Because seed dormancy (seed banks) and local vegetative colonization can obscure the role of the dispersal component in community organization, plots were "sterilized" to further eliminate seed banks and vegetative propagules. Sterilization involved clearing the plots, applying the rinsed fine sand, watering and allowing any potential seedling emergence to occur over a two-week period, and then spraying plots with the systemic herbicide Roundup (Monsanto, St. Louis, Missouri, USA). Because Roundup has a short residence time in the soil, plots were irrigated and covered with landscaping fabric and allowed to rest for two weeks following application of herbicide. This procedure was intended to remove most viable seeds from the soil while leaving microbial communities intact, thereby reducing differences in the influence of microbial communities on plant community attributes between treatments (van der Heijden et al. 2008).

Each year from 2000 through 2004, 1 L of sifted, fresh, river-transported drift was applied to water- and wind- and water-dispersed seed treatments; crumbled sterile peat was applied to plots receiving only wind- dispersed seed rain as an analog to organic material in the drift. Fresh drift (organic material) deposited by spring flows during the current growing season was collected from river margins along each 200-m study reach. Drift was piled onto a plastic sheet and homogenized by hand by removing large pieces of wood and mixing thoroughly. The drift was then sifted through a 2-cm steel mesh to separate propagules from large pieces of organic litter and wood. Drift was again thoroughly mixed to homogenize it, and $1 \mathrm{~L}$ was measured and applied evenly to water dispersal plots and lightly watered. Homogenized drift from the same source was applied to all plots receiving water-dispersed drift at a site. A sun-penetrable cloth exclosure was mounted over the plots receiving only water-dispersed seeds to exclude wind- and animal-dispersed seeds. Exclosures made of water-permeable landscape fabric pinned directly to the ground were applied to all plots each year in late fall to allow for natural flooding of the plots but excluding water-dispersed propagules (Vogt et al. 2004; Fig. 3).

Collected drift containing river-deposited propagules was applied each spring during the years 2000 through 2004. Plots were hand-watered every few weeks during the growing season in 2001 and trenched with a spade annually (spring and fall) to prevent colonization by roots, runners, stolons, and rhizomes. Watering was intended to make conditions suitable for germination and diminish the influence of natural differences in 
moisture between plots on emergence of seedlings. All plots were fertilized once during the first growing season with $9 \mathrm{~g} / \mathrm{m}^{2}$ of a $3: 1: 1$ ratio of NPK solution to accelerate growth to facilitate seedling identification. Using wind exclosures was only possible from 2000 through 2002 due to vegetation growth. At the end of each growing season all vascular plants were identified to species, stems were counted, cover was estimated, and cover of bryophytes was recorded in each plot.

To isolate inherent differences in plot-related factors from the treatment effects we also estimated available moisture, light, and exposure to shear stress (wave or fluvial disturbance). Plot-level variables were measured on an ordinal scale of low to high (1 to 5) annually at the time of species composition measurements. The ordinal responses were intended to provide relative scores for plots and were based upon moisture at the time of measurement, apparent exposure to high-velocity flows when inundated, and the characteristics of overstory and surrounding vegetation. We also measured several sitelevel factors: aspect, insolation, elevation above mean sea level, distance downstream from upstream-most site, number of upstream tributaries, and reservoir surface area (Ume River).

\section{Statistical analyses}

To examine hypotheses 1 and 2, i.e., that numbers of colonizing species should be higher on sites along the free-flowing river and in plots open to long-distance dispersal by water, we tested for differences in plot-level species richness and seedling density between flow regimes (i.e., impoundment, tranquil, and turbulent), between treatments, and over time using repeatedmeasures generalized linear models with a log link function and Poisson distribution. Using the Poisson distribution overcomes many of the assumption violations associated with linear models to count data that may contain many zeros and constrains modeled richness and stem count data to be a zero or positive number. Dispersion (model fit) was assessed using Pearson $\chi^{2} / \mathrm{df}$. Overdispersion implies that there is more variability around the model's fitted values than is consistent with a Poisson formulation. In cases in which overdispersion was present, we used a generalized Poisson distribution, which has an additional parameter (a scale parameter) and can be more appropriate in such cases (Joe and Zhu 2005). A first-order autoregressive covariance structure was used for the time component with river and treatment as fixed effects and elevation blocks as a random effect. The Kenward-Roger correction was used to obtain appropriate degrees of freedom as is recommended for repeated-measures analysis (Littell et al. 2006). If there was a significant interaction between time and richness or stem density, individual models were fitted within years and multiple comparison tests were performed (Tukey's adjustment). In addition, mean richness of plots receiving only winddispersed propagules was compared with the other two treatments (which received water-dispersed propagules) using contrasts.

We evaluated differences in reach-scale species richness as a function of reach type and dispersal treatment through fitting and comparing species accumulation curves that reflect site-cumulative (as opposed to plot average) species richness of rivers and seed dispersal treatments. We tested for differences in site-cumulative species richness between reach types, treatments, and their interactions using repeated-measures generalized linear models with a log link function and Poisson distribution and examined pairwise differences.

In addition to testing for differences in richness at the plot and site levels, we included plot-level covariates to the plot-level generalized linear models and site-level covariates to the site-level models. Site-level variables included available light, available moisture, and exposure to fluvial processes. Because these were semiquantitative variables, we calculated Gower's similarity coefficient for all plots; this similarity measure calculates similarity between plots according to levels of categorical or semi-quantitative traits (Gower 1971). We then conducted a principal coordinates analysis (PCoA) using this resemblance matrix (Legendre and Legendre 1998). The first two axis scores were used as the plotlevel environmental covariate for generalized linear models. Spearman rank correlation indicated that the first PCoA axis largely reflected site moisture $(r=0.80, P$ $<0.0001)$ and to a lesser degree available light $(r=0.38$, $P<0.0001)$ and the second axis represented available light $(r=0.45, P<0.0001)$ and exposure to fluvial disturbance $(r=-0.54, P<0.0001)$. We compared PCoA axis scores between the Ume and Vindel Rivers using $t$ tests. Site-level covariates included elevation of the site above mean sea level (in meters), distance downstream from the furthest upstream site (in kilometers), number of upstream tributary streams, and direct incident radiation (insolation; in megajoules per square centimeter per year), which was calculated using latitude, slope, and aspect of each site following McCune and Keon (2002). The same covariates were used for both rivers except that reservoir surface area (in square kilometers) adjacent to the site was included in the impounded Ume River models. Elevation and distance downstream (position in the catchment) were excluded as covariates due to their correlations with one another and with number of tributaries $(r>0.75, P<$ $0.01)$.

To test the hypothesis that wind dispersal plots should be more similar to adjacent control plots than water dispersal plots (hypothesis 3), we calculated Jaccard's $\left(s_{\mathrm{J}}\right)$ and Bray-Curtis similarity $\left(s_{\mathrm{B}}\right)$ indices for each of the treated plots and their adjacent control. Whereas the $s_{\mathrm{J}}$ index is based upon presence or absence of shared species in the plots, $s_{\mathrm{B}}$ reflects similarities in presence and total abundance of species in plots. To estimate the regional species pool of each river, we fitted species accumulation curves to species lists for all of the 
treatments and controls collectively for all five years. All 168 species identified were included in this estimate. We used a Jackknife 1 estimator and 999 permutations to fit the species accumulation curves. Since the Vindel River had a total of 892 observations (due to sampling of both tranquil and turbulent reaches) and the Ume had 480, we used the Jackknife 1 estimate of richness for 480 plots for the Vindel species pool to account for species-area relationships.

Turnover provides an index for the dynamics of species composition from one year to the next. To test our hypothesis regarding differences in species turnover between rivers and between treatments (hypothesis 4), interannual species turnover was calculated using plotlevel extinction and colonization from one year to the next (MacArthur and Wilson 1967):

$$
t_{\mathrm{MW}}=\frac{I+E}{2}
$$

where $t_{\mathrm{MW}}$ is species turnover rate, $I$ is the number of new species appearing in plots from time $t-1$ to $t$, and $E$ is the number of species disappearing from the plots over the same time interval. We also calculated turnover normalized by species richness at time $t$ and $t-1$ (Bakker et al. 2003). Species turnover rate was calculated as

$$
t_{\mathrm{B}}=1-\frac{\text { species in common }(t-1 \rightarrow t)}{\frac{\mathrm{TN}(t-1)+\mathrm{TN}(t)}{2}}
$$

where $t_{\mathrm{B}}$ is species turnover rate in a specific year $(t)$. The numerator is the number of species present in both year $t$ and year $t-1$. This number is divided by the average total number of species (TN) in both years. After subtracting the result from 1 , a value between 1 (indicating that all species are new) and 0 (species composition is identical in both years) is yielded (Bakker et al. 2003). Repeated-measures general linear models (ANOVAs) were used to test for differences through time and between reach types, treatments, and their interactions. Pairwise tests (Tukey's adjustment) and linear contrasts were conducted when appropriate.

Species accumulation curves were fitted using EstimateS 7.5.0 software (Colwell 2004). SAS version 9.3 (SAS Institute, Cary, North Carolina, USA) was used for all other statistical analyses. Unadjusted means (rather than least squares means) are presented \pm SE.

\section{RESULTS}

\section{Plot-scale species richness and seedling density}

Over the five years of the study, 19702 seedlings of 168 species were identified and counted, and percent cover was estimated in the dispersal treatment plots. Seedling density (measured as the number of stems per square meter) was not significantly different among treatments $\left(F_{2,204}=2.3, P=0.10\right)$ or as a function of reach type $\left(F_{2,204}=2.1, P=0.12\right)$, nor was the interaction between reach type and treatment significant $\left(F_{4,204}=1.1, P=0.35\right)$ in repeated-measures generalized linear models (Appendix A). The model fit the data well $\left(\chi^{2} / \mathrm{df}=1.1\right)$ and the repeated-measures parameter estimate was large relative to its SE, indicating an important time effect. Stem density was higher in the treatments that included water dispersal ( $32 \pm 6$ stems/ $\mathrm{m}^{2}$ ) compared to plots receiving only wind-dispersed propagules $\left(15 \pm 4 \mathrm{stems} / \mathrm{m}^{2}\right)$ in the first year of the study. Initial stem density (in 2000) was almost four times as high in water dispersal plots $\left(56 \pm 15 \mathrm{stems} / \mathrm{m}^{2}\right)$ compared to wind dispersal plots $\left(15 \pm 6\right.$ stems $\left./ \mathrm{m}^{2}\right)$ on the impounded reaches. Stem density increased to $68 \pm$ 12 and $57 \pm 10$ stems $/ \mathrm{m}^{2}$ in water and wind dispersal plots, respectively, on the impounded reaches by the end of the study.

Along the free-flowing tranquil reaches, stem density in water- and wind-dispersed plots was approximately the same in the initial year of colonization ( $22 \pm 4$ and $22 \pm 9 \mathrm{stems} / \mathrm{m}^{2}$, respectively) and increased three- and fourfold in the five years of the study to $66 \pm 13$ and 93 $\pm 21 \mathrm{stems} / \mathrm{m}^{2}$. Along the free-flowing turbulent reaches, stem density in water and wind dispersal plots was higher in the water dispersal plots compared to wind dispersal plots $\left(14 \pm 3\right.$ and $8 \pm 3$ stems $\left./ \mathrm{m}^{2}\right)$ and increased three- and fourfold in the five years of the study to $94 \pm 13$ and $94 \pm 17 \mathrm{stems} / \mathrm{m}^{2}$. The highest density of stems observed was in the combined wind and water dispersal treatment on the free-flowing turbulent reach $\left(124 \pm 22 \mathrm{stems} / \mathrm{m}^{2}\right.$ in 2004) and the impounded reach type (75 $\pm 18 \mathrm{stems} / \mathrm{m}^{2}$ in 2002). Neither vascular nor nonvascular plant cover varied as a function of reach type $\left(F_{2,219}=1.6, P=0.2\right.$ and $F_{2,220}=1.8, P=$ $0.2)$. Vascular plant cover was highest in plots receiving water-dispersed propagules (contrast, $P=0.02$ ). Bryophyte cover did not vary as a function of treatment $\left(F_{2,220}=1.0, P=0.4\right)$, but increased from an average of $0.2 \% \pm 0.2 \%$ to $16 \% \pm 1.8 \%$ from the first to the final year of the study.

Plot-scale species richness varied significantly by treatment over the five years observed $\left(F_{2,193}=6.1, P\right.$ $=0.003)$, as well as by reach type $\left(F_{1,193}=7.2, P=\right.$ $0.001)$, and the interaction was insignificant $\left(F_{2,193}=1.7\right.$, $P=0.1)$ and the model fit well $\left(\chi^{2} / \mathrm{df}=0.90\right.$; Fig. 4). Species richness in the wind dispersal treatment compared to the other two treatments indicated that the wind dispersal treatment had significantly lower species richness (contrast; $P=0.0006$ ) over the five years compared to the other treatments (Fig. 4). Tukey's comparisons indicated that free-flowing reach types did not differ from one another $(P=0.6)$, but the impounded reaches differed from both tranquil $(P=$ $0.02)$ and turbulent $(P=0.0007)$ free-flowing reaches. Because species richness varied significantly as a function of time, we examined each year of the study individually.

Treatment effects were significant over all reach types $\left(F_{2,205}=32.5, P<0.0001\right)$ following the first growing 
a) Impounded Ume River, reservoir

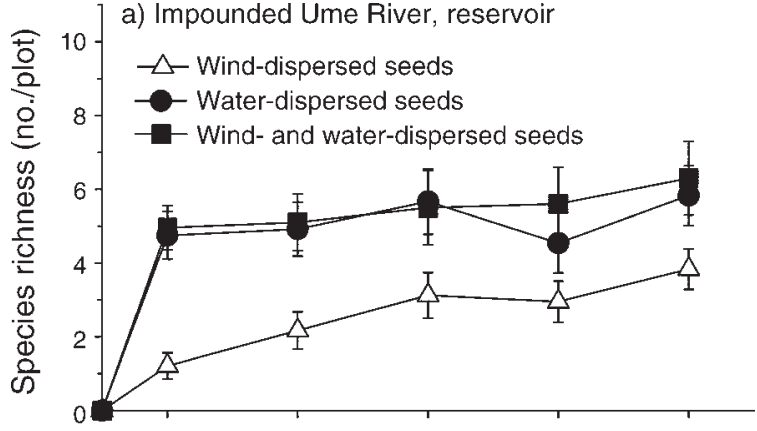

b) Free-flowing Vindel River, tranquil reaches

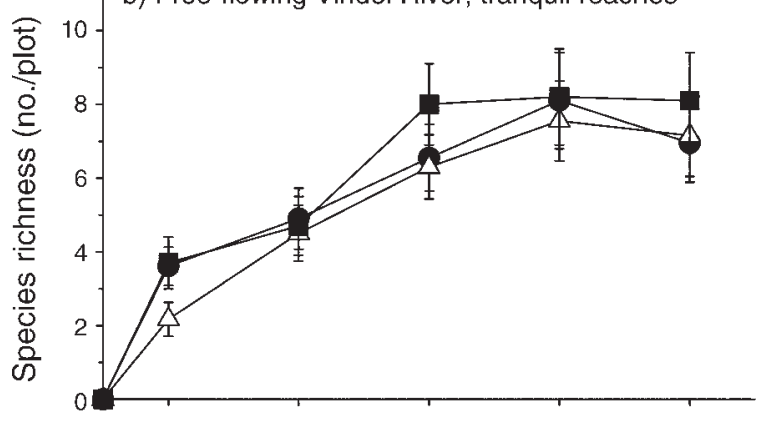

c) Free-flowing Vindel River, turbulent reaches

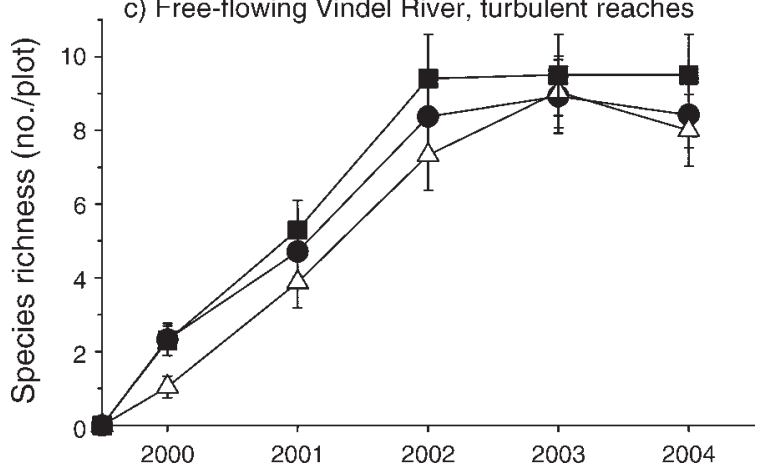

FIG. 4. Species richness (mean $\pm \mathrm{SE}$ ) in plots receiving wind-dispersed, water-dispersed, and wind- and water-dispersed seeds on the impounded Ume River and the free-flowing Vindel River from 2000 through 2004.

season (2000). Species richness was significantly higher in the water dispersal and wind and water dispersal plots on the first year of establishment along the free-flowing turbulent reaches $(P<0.05$, Tukey's test; Fig. 4). Overall species richness was 1.7 to 4 times higher in water dispersal plots compared to wind dispersal plots in this first year of colonization. The mean richness of plots colonized by water-dispersed seeds remained higher than wind dispersal plots throughout the study along the impounded reaches of the Ume River. Plot-level species richness converged in dispersal treatments along the free-flowing Vindel River by 2001 along tranquil reaches and by 2003 along turbulent reaches (Fig. 4). Levene's tests for equal variance indicated that the impounded reaches had the highest variability in plot-scale species richness after accounting for changes through time and that the free-flowing turbulent reaches had the lowest variance. Multiple comparisons using Tukey's adjustment indicated that variance of the impounded reaches was significantly higher than the turbulent reaches $(P=$ $0.02)$ but not the tranquil reaches $(P=0.1)$.

Shannon diversity $\left(H^{\prime}\right)$ significantly differed among treatments $\left(F_{2,282}=3.5, P<0.03\right)$ and reach types $\left(F_{2,282}=15.2, P<0.0001\right)$ over the five years of the study, being highest along free-flowing reaches and in the treatments that received water-dispersed seeds (Appendices A and B). Evenness varied as a function of reach type $\left(F_{2,208}=5.7, P=0.004\right)$, being highest along free-flowing river reaches, but did not vary as a function of treatment $\left(F_{2,208}=1.0, P=0.4\right)$.

In models in which we included plot-level covariates to account for environmental variation, we found that differences in richness between dispersal treatments remained significant for the first two years of the study along impounded reaches of the Ume River. Plot-level environmental conditions (PCoA axis 1 scores representing soil moisture) explained significant amounts of variation in plot-level richness in all years of the study $(P<0.05)$ and became increasingly significant through time (Appendix C). Soil moisture was an increasingly important predictor of richness throughout the study along the impounded Ume River, with moister sites maintaining higher species richness. Treatment effects better explained variation in richness in the first year of the study along the turbulent and tranquil reaches of the Vindel River $\left(F_{2,127}=4.3, P=0.02\right)$. In the last two years of the study richness increased significantly with increasing light intensity and decreasing fluvial disturbance along both reach types of the Vindel River (Appendix C).

Variability in available soil moisture, light, and fluvial activity was greater along the Vindel than the Ume River. Ume and Vindel River PCoA axis scores (plotlevel environmental conditions) were significantly different for both PCoA axis $1(t=6.7, P<0.0001)$ and PCoA axis $2(t=2.4, P<0.017)$. Plots on the freeflowing Vindel River spanned a range of 1.27 and 1.30 units along PCoA axes 1 and 2, respectively, whereas the impounded Ume River plots spanned 0.72 and 0.84 PCoA axis units.

\section{Site-scale species richness}

Cumulative species richness at the site scale was significantly different over time and between reach types $\left(F_{2,40}=11.0, P<0.0001\right)$, but not between treatments $\left(F_{2,40}=2.1, P=0.1\right)$; the interaction between river and treatment was also not significant $\left(F_{2,40}=1.1, P<0.4\right.$; Figs. 5 and 6$)$. Multiple comparisons indicated that the two classes of freeflowing reaches differed significantly from the impounded reaches $(P<0.001)$, but not from one another. Contrasts comparing the two treatments that received water-dispersed seeds (pooled) to the wind 

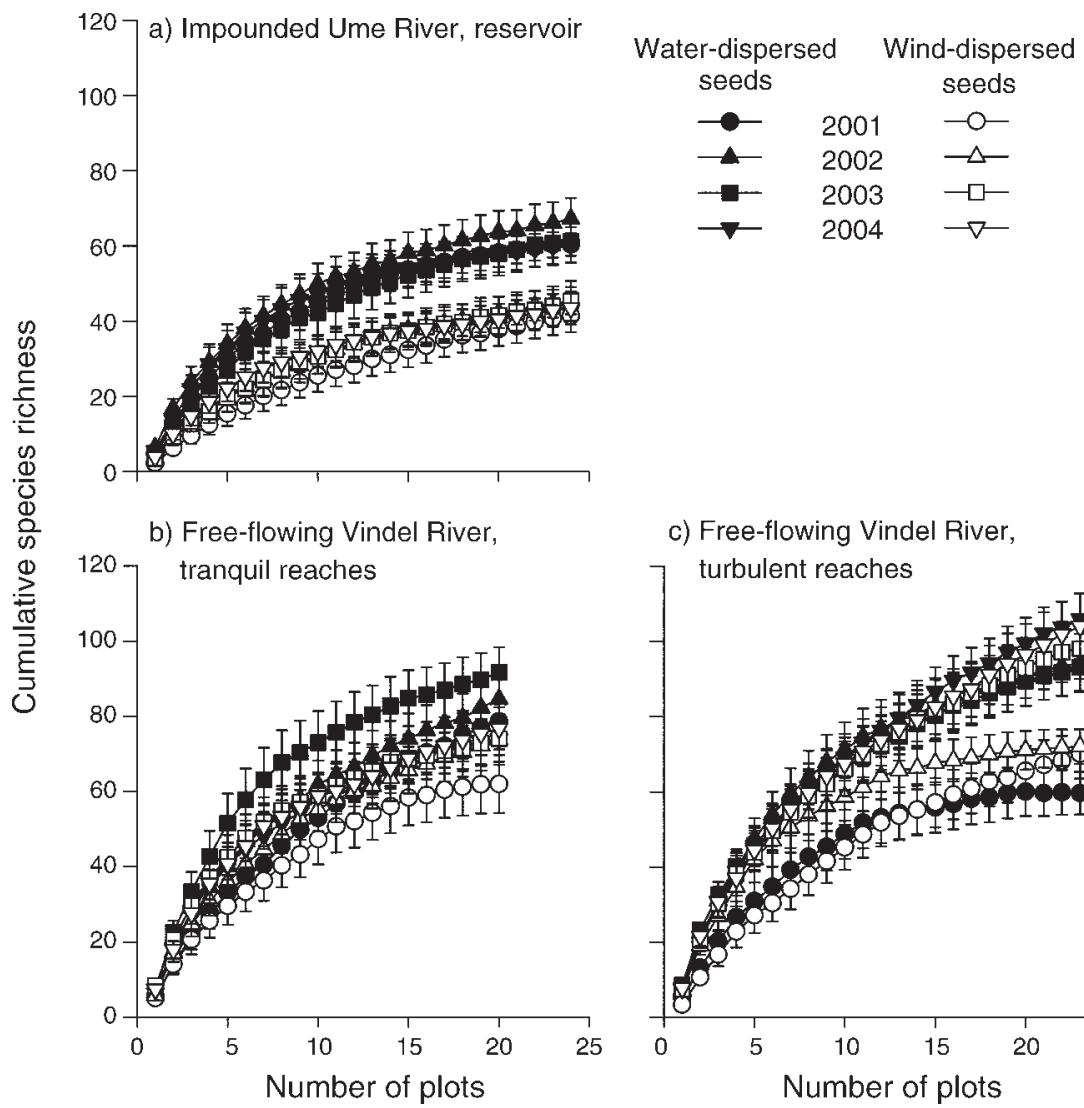

c) Free-flowing Vindel River,

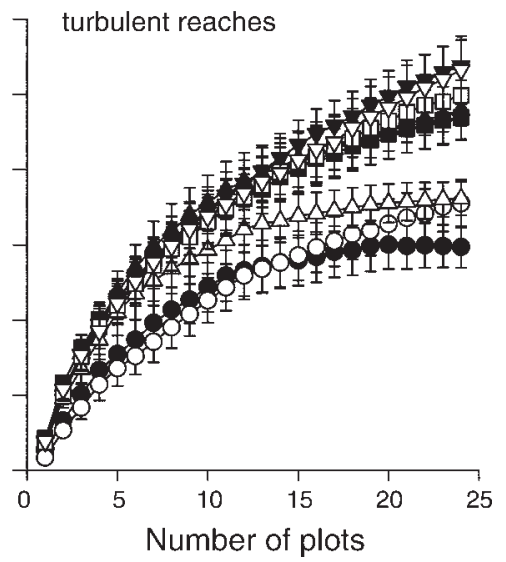

FIG. 5. Species accumulation curves for (a) the regulated Ume River and (b) tranquil and (c) turbulent reaches of the freeflowing Vindel River. Cumulative species richness is a function of the cumulative number of plots (added in randomized order) for the treatment and reach type specified.

dispersal treatment indicated that the wind dispersal treatment had lower cumulative richness than the other two treatments $(P=0.05)$ after accounting for repeated measures through time. The average site-level cumulative richness on the free-flowing tranquil reaches was $19 \pm 1.6$ and was $20 \pm 1.7$ on turbulent free-flowing reaches and $11 \pm 1.2$ on the impounded reaches in the final year of the study.

Because species richness along the impounded and free-flowing reaches differed, each was analyzed separately for treatment effects (Appendix D). Since species richness between tranquil and turbulent reaches was not significantly different, these reach types were analyzed together. Treatment effects were significantly different on the impounded reaches in all years as were the covariates to various degrees. Insolation and number of tributaries were significant predictors of richness along the impounded reaches in all years (except in 2003). The only significant covariate in models of site-level richness on the Vindel River was number of upstream tributaries $(P<0.05)$, which was inversely related to site-level richness in all years except 2001.

\section{Similarity of treatments and standing vegetation and composition of treatments}

The average Jaccard's species similarity $\left(s_{\mathrm{J}}\right)$ values per plot between treatments and adjacent standing vegetation (control plots) were significantly different over the period of record between reach type $\left(F_{2,226}=3.5, P=\right.$ $0.03)$ but not as a function of treatment $\left(F_{2,226}=0.11, P\right.$ $=0.3)$ or their interaction $\left(F_{4,226}=1.0, P=0.4\right.$; Appendices A and B). Mean similarity to controls was higher along the free-flowing turbulent reach compared to the impounded reach. There were also differences between Bray-Curtis similarities $\left(s_{\mathrm{B}}\right)$. These varied over time and reach $\left(F_{1,216}=7.0, P<0.001\right)$, but not by treatment $\left(F_{2,216}=0.1, P=0.9\right)$ or their interaction $\left(F_{2,216}=1.4, P=0.2\right)$ in repeated-measures analysis. Least squares mean $s_{\mathrm{B}}$ after adjusting for the effect of time was twice as high along the free-flowing turbulent and tranquil reaches of the Vindel compared to the impounded Ume River. Wind dispersal plots were more similar to adjacent controls in all years along tranquil reaches of the Vindel River. Along turbulent reaches of the Vindel River, plots receiving water-dispersed propagules were more similar to controls in all years, but 

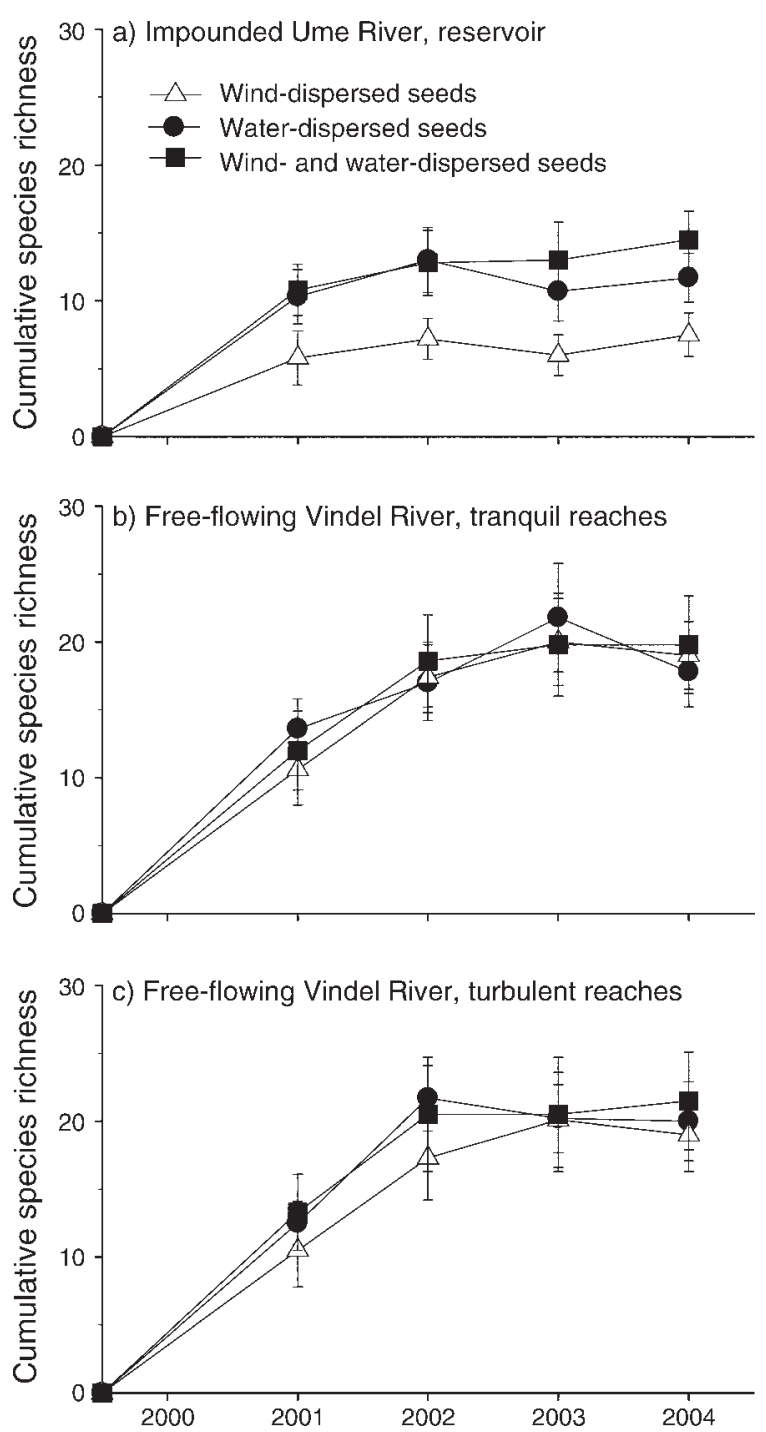

FIG. 6. Cumulative reach-scale species richness of plots colonized by wind- and water-dispersed propagules along (a) the impounded Ume River and (b) tranquil and (c) turbulent reaches of the free-flowing Vindel River. Cumulative species richness is a function of the cumulative number of plots (added in randomized order) for the treatment and reach type specified.

only significantly so in 2001. The similarity between treated plots and controls was higher along the freeflowing reaches compared to the impounded reaches every year of the study $(P<0.05)$. In no year were the wind dispersal plots more similar than the plots receiving water-dispersed propagules along the impounded reaches.

Relationships between cumulative species richness of each treatment within each river and cumulative species richness of the control plots revealed that wind dispersal plots were more strongly associated with standing vegetation at sites than water dispersal plots. This was true for all years, and all models were significant at $P<$ 0.05 . The relationship between cumulative species richness of treatments within sites and cumulative richness of control plots of sites was significant for all treatments, but the relationship was consistently stronger for the wind dispersal plots $\left(r^{2}=0.36-0.86\right.$ for wind and $r^{2}=0.23-0.71$ for water dispersal treatments; $P<$ $0.05)$.

In examining species composition between treatments at the sites, we documented some qualitative differences. Species that were most responsible for the separation (dissimilarity) of wind-dispersed, water-dispersed, and water- and wind-dispersed treatments along the Vindel River included Deschampsia cespitosa, Molinia caerulea, and Solidago virgaurea, which were more frequent in wind dispersal plots. Calamagrostis-Agrostis, Carex spp., Juncus filiformis, Cardamine pratensis, and Valeriana sambucifolia were more frequent in water dispersal plots along the Vindel River. Carex spp. (primarily $C$. acuta), Festuca ovina, Galium palustre, and Prunella vulgaris were more common in water dispersal plots along the Ume River. Vaccinium myrtillus, Oxalis acetosella, and Equisetum spp. were more frequent in wind dispersal than water dispersal plots on the Ume River. Seeds of species with long floating duration (diaspores floating $>2$ d; Romell 1938) were overrepresented in the water dispersal plots along both reaches of the Vindel River, including Carex canescens, Angelica archangelica, A. sylvestris, Betula pubescens, Festuca ovina, F. rubra, Filipendula ulmaria, Galium boreale, G. palustre, Geranium sylvaticum, Hierochloë spp., Juncus filiformis, Luzula multiflora, Molinia caerulea, Pedicularis palustris, Parnassia palustris, Potentilla palustris, Populus tremula, Ranunculus repens, Solidago virgaurea, Trollius europaeus, Valeriana sambucifolia, Viola biflora, and $V$. canina.

The number of unique species (those not occurring in other treatments) was five times greater in the Ume River water dispersal plots than in the wind dispersal treatments. There were 29 species unique to the water dispersal plots along the Ume and only six species unique to the wind dispersal plots. There were 14 species unique to the water dispersal plots along the tranquil reaches of the Vindel River and 11 species unique to the wind dispersal plots. Along turbulent reaches of the Vindel River there were nearly twice as many unique species (20) in the water dispersal treatments compared to the wind dispersal treatments (12 unique species).

\section{Species turnover}

Species turnover unadjusted for species richness $\left(t_{\mathrm{MW}}\right.$; MacArthur and Wilson 1967) was higher along reaches of the Vindel compared to the Ume River in both wind and water dispersal treatments in all years, but turnover did not differ by treatment along the tranquil and turbulent reaches of the Vindel River (Appendices A and B). Species turnover unadjusted for species richness remained high in 2001-2002 and 2002-2003 along the Vindel, but dropped by $30 \%$ in both treatments during the 2003-2004 time period (Fig. 7). It was higher in the 


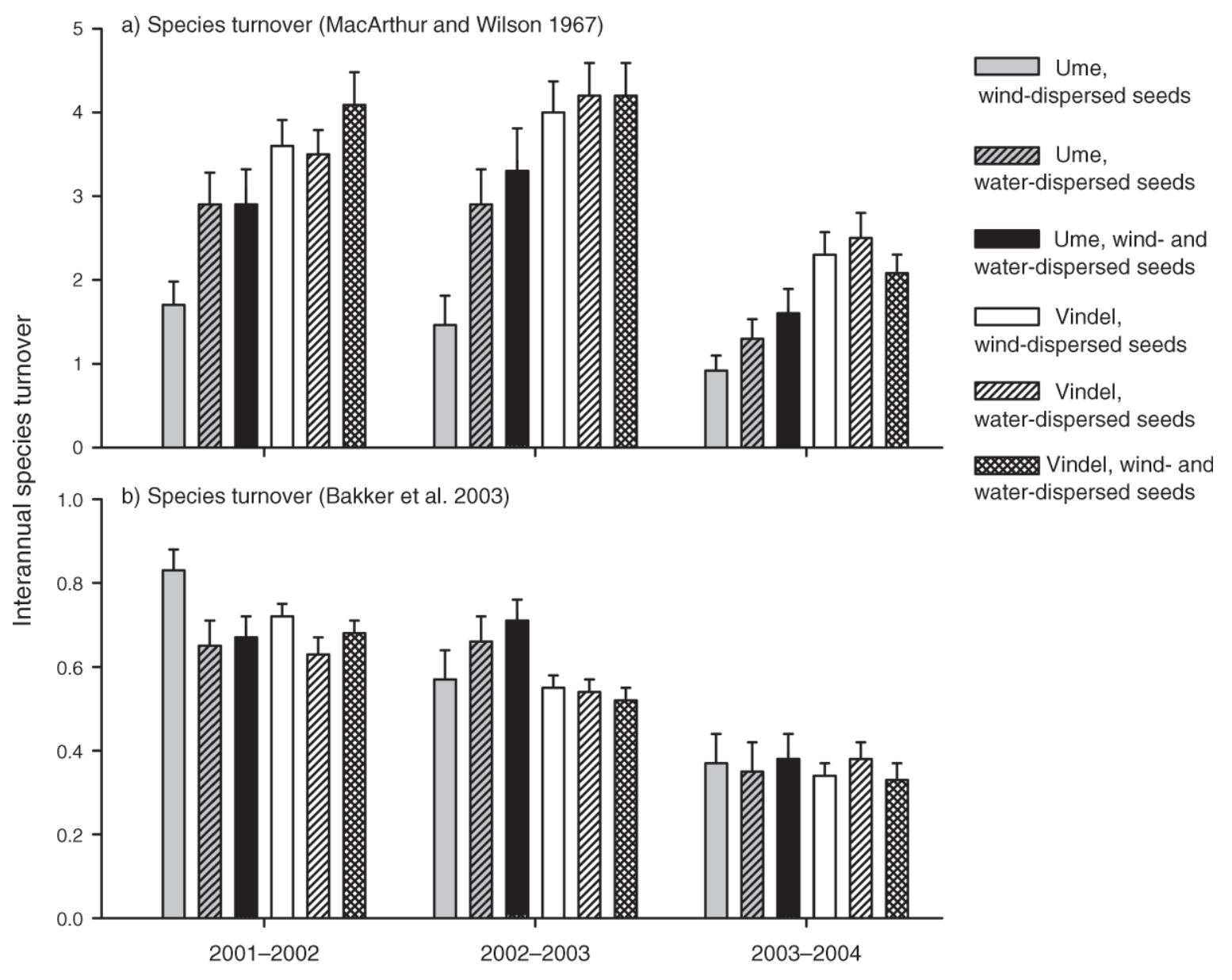

FIG. 7. Interannual species turnover (mean + SE) using (a) the measure of MacArthur and Wilson (1967) and (b) turnover rate adjusted for site species richness (Bakker et al. 2003) for plots colonized only by wind-dispersed propagules or water-dispersed propagules along the free-flowing Vindel River and the impounded Ume River. For comparison, mean cumulative richness of the control plots (undisturbed vegetation) at the site scale was $10 \pm 1.7$ species on the impounded reaches and $19 \pm 2.0$ and $27 \pm 3.2$ species on the tranquil and turbulent reaches of the free-flowing river, respectively, in 2004.

water dispersal plots in all years along the Ume River, remaining about the same during the first two periods measured (2001-2002 and 2002-2003), falling in both treatments by almost 50\% during the 2003-2004 period. In contrast, interannual species turnover adjusted for species richness $\left(t_{\mathrm{B}}\right.$; Bakker et al. 2003) did not differ between reaches, treatments, or their interaction but fell by $20-30 \%$ per year during the study (Appendix A).

\section{DisCUSSION}

\section{Local vs. regional seed sources: treatment effects on richness}

The findings of this study support the hypothesis that hydrochory is an important process for the establishment of riparian plant communities along both freeflowing and regulated rivers. Plant communities derived from treatments including water-dispersed seeds were more species rich (and diverse) than those derived solely from locally wind-derived seeds averaged over plots and sites growing along the free-flowing and impounded rivers (Appendix A). Our findings from multiple sites, in a range of landscape and fluvial settings (including within impoundments), suggest that water dispersal is an important mechanism for sustaining species-rich communities along river margins. This is particularly true in fragmented systems having low local diversity, as access to hydrochory resulted in richer communities than those derived from local wind- and animal-derived seed sources along reservoir margins. Thus, local diversity was enhanced by receiving propagules from communities growing at other locations within impoundments and their tributaries. The number of unique species (those occurring in one treatment but not in the other at a site) was higher in plots receiving water-dispersed seeds compared to plots receiving only wind-dispersed seeds along both the free-flowing and regulated rivers, suggesting that water dispersal provides an important complement of species to sites.

The convergence in species richness of plots receiving locally derived, wind-dispersed propagules and those 
receiving regionally derived, water-dispersed propagules at our sites along the Vindel River did not support our hypothesis suggesting that there would be sustainably higher richness in regionally derived, water-dispersal plots. The difference in species richness as a function of propagule source was only significant following the first year of colonization on the Vindel River (Fig. 4b). This pattern was similar in the first year of establishment along the Ume River, and then the plots receiving waterdispersed propagules reached apparent equilibrium richness in a single year (Fig. 4a). This asymptote coincides with the mean richness of the control plots along the Ume River ( $4.7 \pm 0.48$ species). It is unlikely that competitive exclusion is responsible for this pattern in our plots as the relationship between total plant cover and species richness remained positive throughout the study. The plots receiving only locally, wind-dispersed propagules have not yet reached equilibrium along the Ume River as they appear to continue to be seed limited, increasing at an average rate of approximately one species every two years (Fig. 4a).

Along the Vindel River, colonization was more rapid in plots with access to regional species pools in both turbulent and tranquil reaches. Initial richness has been shown to be higher in systems with a richer and more connected species pool (e.g., interactive systems) wherein good dispersers reach sites first, but do not necessarily become long-term residents (Morrison 2003, Starzomski et al. 2008). Although average species richness in the control plots along the turbulent reaches was $12.8 \pm$ 0.97 species, species richness in treatments in both the turbulent and tranquil reaches reached a maximum at a value near the average richness of the tranquil control plots in the reach $(8.2 \pm 0.95$ species; Fig. $4 b, c)$.

\section{Species richness between free-flowing and regulated rivers}

Plant communities were richer (and more diverse) both as a plot-scale average and as a site-level cumulative richness along the free-flowing Vindel River than along the heavily regulated Ume River when evaluated over the five-year period. This was true despite the fact that seedling density did not significantly differ between the two rivers overall. Although the "regional species pool" on the Vindel was higher (159 species total) than on the Ume River (144 species) from cumulative counts of our study plots, this $10 \%$ difference does not alone account for the significant differences in local-level (plot) species richness. Even after five years of colonization and community development, the average species richness in all of the Ume River experimental plots was $5.2 \pm 0.5$ species compared to $8.1 \pm 0.4$ species along the Vindel River. This result supports earlier studies suggesting that although the Ume River catchment contains a similar number of species in its overall species pool (256 species) to the Vindel River (247 species), dams and reservoirs along its course significantly repress the potential species richness of riparian plant communities (Nilsson et al. 1991a, Jansson et al. 2000b). Dams, such as those along the Ume River, are efficient at trapping seeds, obstructing long-distance dispersal, and causing the pool of potential species to be reset at each impoundment (Merritt and Wohl 2006, Brown and Chenoweth 2008).

The observed similarity in seedling density along the Vindel and Ume Rivers suggests that higher richness along the Vindel River is not simply an artifact of a higher density of seeds introduced to the plots. It is likely that the Ume River receives as many seeds (or more due to high surface area and trapping efficiency of reservoir surfaces) as the Vindel River, but that these propagules are derived locally from the vegetation growing along reservoir shores and from (small) tributaries to single reservoirs (Bång et al. 2007) rather than from throughout the Ume River catchment. This fragmentation prevents seed accumulation along the length of the Ume River and isolates each reservoir, causing communities within each reservoir to operate "hydrochorically" independently of one another (Nilsson et al. 1994, Jansson et al. 2000b). Furthermore, seeds are transported by waves and prevailing winds that move seeds around on reservoir surfaces (many of which sink) and are then deposited in drift lines along windward shores. In this way, seeds with longer floating ability are have an advantage, and there is nonrandom (sorted and directional) distribution of seeds along margins of both free-flowing rivers (Nilsson et al. 2002, Chambert and James 2009) and run-of-river impoundments (Jansson et al. 2000a).

In addition to isolating local plant communities from regional species pools, local factors likely limit diversity along reservoir shorelines. The plots on the reservoir margins along the Ume River were placed along shorelines that lack the dynamic fluvial processes and microhabitats that historically characterized Ume River margins and persist along the Vindel River today. Most of the current reservoir margins along the Ume River are above the former river channel and formed in upland boreal forest following reservoir filling. These areas have acidic soils and are dominated by conifers (primarily Pinus sylvestris and Picea abies) as well as Vaccinium spp. Habitat simplification along the Ume River most certainly plays an important role in the lower plant diversity in riparian areas. Our analysis of available light, moisture, and exposure of plots to fluvial disturbance illustrates that environmental conditions along the Ume River are significantly more homogeneous than along the fluvially active Vindel River. In addition, regional species pools have equal access to tranquil and turbulent reaches of the Vindel River. Higher species richness along turbulent reaches is likely due in part to higher substrate heterogeneity (Renöfält et al. 2007), which provides more microhabitats to accommodate a wider range of species and more opportunities due to higher propagule trapping ability (Nilsson et al. 1991b, Andersson et al. 2000a), which act in concert to enhance species richness. 
Water dispersal was proportionally more important for maintaining local-scale (plot-scale) richness than wind dispersal along the fragmented river compared to the free-flowing river. There are two major reasons for this difference. (1) Along a free-flowing river, hydrochory has been in operation for millennia, so many of the species that might only occasionally benefit from long-distance dispersal have already become established in the local flora. In the regulated river, such "species sinks" may have gone extinct as a result of the hydroelectric development that significantly modified, removed, or submerged the pre-impoundment, riparian vegetation (Nilsson et al. 1991a, Jansson et al. 2000a, b). (2) The region from which hydrochory can derive propagules is substantially smaller in the regulated compared to the free-flowing river, thus corroborating our hypothesis suggesting that river fragmentation affects the area that would potentially contribute species and is reflected in local plant community richness. It is likely that the current communities along the Vindel River are sufficiently species rich to provide the propagules so that new sites are able to establish quickly and achieve and maintain a high level of species richness locally. This does not diminish the importance of hydrochory along free-flowing rivers, but it does provide insight into the temporal and spatial scales over which its influence is detectable. The introduction of propagules from elsewhere and the introduction of unique species from upstream sources are likely important in enhancing site-level diversity and contributing to potential diversity of river margins along the Vindel River.

Species similarity to standing vegetation controls

We hypothesized that the wind dispersal plots would be more similar to local standing vegetation at the sites than the communities formed from water-dispersed seeds or a combination of wind- and water-dispersed seeds. Although Jaccard's similarity $\left(s_{\mathrm{J}}\right)$ was highest in almost all cases between wind dispersal plots and standing vegetation, the relationship was not significant (Appendices A and B). The highest average $s_{\mathrm{J}}$ observed $\left(s_{\mathrm{J}}=0.77\right)$ was between the wind dispersal plots and local controls (Vindel River in 2003), which was high compared to average similarity of the water dispersal plots to the control $\left(s_{\mathrm{J}}=0.24\right)$ but not significantly so (Tukey's test, $P>0.05$ ). Bray-Curtis similarity was higher for wind dispersal plots along tranquil reaches of the Vindel River in most years, but this was not the case for either the turbulent reaches of the Vindel River or the Ume River.

One possible explanation for this counterintuitive lack of a strong and significant effect is that many species in the vegetation surrounding the plots also were present as seeds in the river-transported drift deposits. Many species that would be considered wind dispersed (because of adaptations such as tufted trichomes or wings that decrease fall velocity in air) land on the water or along moistened shorelines and end up in the locally deposited drift. Alternatively, species commonly present as seeds in the drift have established local, riparian populations from which they have established secondary populations by dispersal vectors other than water, thus contributing to the local seed rain received in the wind dispersal treatment. Wind-dispersed species (trees and shrubs) that contribute significantly to wind-dispersed seed pools (e.g., Alnus incana, Betula pubescens, Picea abies, Pinus sylvestris, Populus tremula, and Salix spp.) were in fact all marginally more abundant in the wind dispersal treatments than in the treatments receiving drift along both the Ume and the Vindel Rivers in the final year of sampling (the exception being Picea abies, which was abundant in all three treatments). However, because these species are all effective wind dispersers, many of their seeds also became "incidental hydrochores" and ended up in treatments only receiving drift material.

Because of this inherent mixing of facultative and obligate hydrochores as well as incidental hydrochores in the drift, one might expect communities emerging solely from water-dispersed seeds to have significant overlap in species composition with wind dispersal plots, as we observed. One might also assume that because waterborne drift samples contain seeds from all of these sources they would tend to be richer in species because of this fact alone, ignoring the role of upstream sources and long-distance dispersal. This is the case along the reservoirs on the Ume River, where meta-populations of wind- and water-dispersed plants from various points along the shores collectively deposit seeds on water surfaces. These seeds are sorted, favoring long-floating species (Jansson et al. 2000a), and deposited as drift on windward shores. Relatively species-poor communities that have formed since the filling of the reservoirs along the Ume River likely benefit tremendously from waterdispersed seeds from elsewhere, even from metacommunities growing along nearby shores.

Along free-flowing rivers such as the Vindel that have maintained species-rich plant communities through time, the local standing vegetation is already speciesrich and contributes to the rich local hydrochoric seed pool in the drift. In this way, the plant communities growing along free-flowing rivers such as the Vindel River may benefit from hydrochory, but may not rely as heavily on this process to maintain species-rich communities over short timescales (less than five years) as sites with restricted local species pools. The benefits of hydrochory to both free-flowing rivers such as the Vindel and regulated systems such as the Ume River likely lie in accelerating colonization and establishment through offering higher concentrations of seeds to recently disturbed sites. The input of seed-laden drift to riparian sites ensures connectivity to meta-populations and meta-communities that might occur within connected water bodies. The added benefits along freeflowing rivers include (1) connectivity between distant meta-populations and meta-communities throughout 
the river network and (2) stochastic long-distance dispersal events that occasionally introduce new species to the local vegetation.

Concentrations of water-dispersed seeds (emerging as seedlings in the plots) were high $\left(56 \pm 15 \mathrm{stems} / \mathrm{m}^{2}\right)$ on the Ume River in the initial years of establishment and the richness of this seed pool was similar $(4.8 \pm 0.6$ species) to wind and water dispersal plots $(5.0 \pm 0.6$ species). A few species were overrepresented in the drift in these samples (e.g., Betula pubescens [38\% of water dispersal plots], Carex acuta [50\%], and Pinus sylvestris [25\%]). Jansson et al. (2005) noted five times higher concentration (78 \pm 7.6 seedlings/L of drift) and three times higher richness $(15.4 \pm 0.9$ species $)$ of seedlings emerging from drift samples taken along Ume River reservoir margins than we documented. Jansson et al.'s (2005) emergence results may provide close approximation of the true number of seeds and species ("potential emergence") in the drift because seedling emergence was conducted on common garden plots under controlled conditions. Our study measured "realized emergence" under field conditions. Subjecting propagules to true field conditions provides a filter so that species with germination and establishment requirements that were not met by site conditions either did not emerge or did not persist in plots.

Jansson et al. (2005) counted $389 \pm 99.6$ seedlings/L emerging from drift samples from margins of the Vindel River in 1997, with a concentration of $12.1 \pm 0.9$ species per sample. Such a high concentration of seeds increases the likelihood of some seeds becoming established due to the mass effect alone (sensu Shmida and Wilson 1985), but such concentrations of seedlings $\left(\sim 1\right.$ seedling $/ \mathrm{cm}^{2}$ translated to our experimental plots) have been shown to run the risk of high mortality due to intra- and interspecific competition and mortality caused by fungal growth in drift (Vogt et al. 2007). Indeed, $80 \%$ of these seeds were from a single species, C. acuta, suggesting that interspecific competition would be a factor. We did not observe such high seed/seedling concentrations emerging in our water dispersal plots along the Vindel River $\left(77 \pm 7.4\right.$ and $96 \pm 11 \mathrm{stems} / \mathrm{m}^{2}$ in water dispersal plots and wind and water dispersal plots, respectively, in 2004), nor did we encounter such high numbers of species $(7.8 \pm 0.7$ and $8.8 \pm 0.8$ species, in water dispersal plots and wind and water dispersal plots, respectively, in 2004). We did document more unexpected species that did not occur at our sites other than in our water dispersal plots and attributed them to longdistance dispersal from elsewhere.

It is well understood that propagules dispersed by water have a dispersal kernel conforming to a leptokurtic or inverse log distribution with the center of mass of the distribution near the propagule source and a long, narrow tail representing rare, long-distance dispersal events (Johansson and Nilsson 1993, Groves et al. 2009, Nilsson et al. 2010). Levine (2003) noted that most patches along a river in California were colonized by propagules from sources within only $100 \mathrm{~m}$ upstream. Structurally complex rivers (such as the Vindel River) are efficient at trapping water-dispersed seeds along hydraulically complex reaches and areas with many emergent objects (e.g., cobbles and plant stems; Schneider and Sharitz 1988, Nilsson et al. 1991b, Merritt and Wohl 2002, Gurnell et al. 2007). Areas of high propagule trapping efficiency have been associated with more species-rich plant communities both in simulations (Merritt and Wohl 2002) and in field experiments (Andersson et al. 2000b). Indeed, trapping efficiency should play some role (in conjunction with habitat complexity and disturbance) in the significantly higher species richness associated with turbulent reaches of the Vindel River (Figs. 4-6; Nilsson et al. 1991a), which exhibit more complex channel morphology, substrates (Renöfält et al. 2007), and hydraulics than tranquil reaches.

Though less probable, long-distance dispersal events by hydrochores (and seed mimics) have been documented in field experiments ranging in dispersal distance from $6 \mathrm{~km}$ (Boedeltje et al. 2003) to as far as $152 \mathrm{~km}$ (Andersson et al. 2000b). The alpine species that we observed below their known elevation limits in our experimental plots were likely long-distance dispersers. We noted a few occurrences of alpine species below their continuous distribution in upland vegetation that were not present elsewhere on the site. These species included Thalictrum alpinum (encountered $195 \mathrm{~m}$ above sea level) and Viola biflora $(230$ and $339 \mathrm{~m})$. Their occurrences were rare (1-5) and only located in the water dispersal treatments along the Vindel River. As shown by Danvind and Nilsson (1997), several alpine species have extended their distribution limits downstream along the Vindel, but these occurrences do not show any obvious relationship with the length of time their propagules can float.

\section{Turnover}

Higher numbers of seeds delivered to sites via hydrochory could increase species richness through the mass effect (sensu Shmida and Wilson 1985), elevating species turnover through time by introducing species into sink habitats where they suffer frequent extinctions. Alternatively, hydrochory may reduce turnover by rescuing populations that otherwise would become periodically locally extinct (the "rescue effect"; Brown and Kodric-Brown 1977). Colonization is mediated by the availability of habitat and propagules; extinction is driven by factors that physically remove individuals (e.g., disturbance), as well as factors that cause mortality, such as disease and competition. Source-sink dynamics might rescue species prone to localized extinction (e.g., as a result a catastrophic flooding). Classic island biogeography theory predicts that larger "islands" (e.g., more numerous species pools) are characterized by lower extinction rates and thus show lower turnover. However, if immigration rates are also 
high due to trapping ability of the "island" ("target effect," sensu Gilpin and Diamond 1976), colonization might be higher, leading to elevated turnover. High turnover can also result from individual species that are efficient dispersers and colonizers, but fail to become established and are caught in a "do loop" of germination and mortality.

We suspected that turnover would be higher along the free-flowing river due to annual flooding, occasional extreme floods, and a rich seed source. Using the classic island biogeographic definition of turnover that examines absolute turnover at the plot scale (MacArthur and Wilson 1967), this was the case (Fig. 7). We found that the turnover was higher along the Vindel River compared to the Ume River regardless of dispersal treatment. Species turnover in wind, water, and wind and water dispersal plots along the Vindel River suggests that colonization and extinction are no lower in plots that receive water-dispersed propagules than in those receiving wind-dispersed propagules. This is likely due to the fact that riparian vegetation is already species-rich along the Vindel River and that populations at the reach or segment scale along free-flowing rivers rescue locally removed populations from becoming locally extinct for any length of time.

Although we did not find any relationships between site average turnover and reservoir size or number of tributaries entering reservoirs on the Ume River, both number of upstream tributaries and distance downstream were inversely correlated to species turnover $(r=$ $-0.44, P=0.004$ and $r=-0.31, P=0.007$, respectively). The implication is that turnover decreases in sites with a larger pool of potential species, despite disturbancerelated mortality, assuming that potential richness increases in a downstream direction along free-flowing rivers (Nilsson et al. 1991a). However, when we examined turnover using an approach more consistent with meta-population theory (Hanski and Simberloff 1997, Bakker et al. 2003), which examines turnover on a per species basis, we found that the high turnover on the Vindel River and the water dispersal Ume River plots may be an artifact of the higher species richness (Fig. 7). After adjusting for species richness, turnover was about the same on the Vindel and Ume Rivers and in all the dispersal treatments (Fig. 7). Using either measure of turnover, our findings do not support the suggestion made by Jansson et al. (2005) that shorelines along impoundments should experience higher interannual species turnover due to disturbance-related mortality, at least not at the riparian elevation of the experimental plots. It is likely that hydrochory enhances richness over longer time periods through chance introduction of propagules of species not present at a site and through helping to balance extinction of a species from a site with colonization through long-distance dispersal from elsewhere (Merritt and Wohl 2006). Hydrochory is also very important for those species that have specialized traits for floating and dispersing by water but have limited ability to disperse by other means (e.g., Pedicularis sceptrum-carolinum, Pinguicula vulgaris, Carex spp., and Juncus spp.).

\section{CONCLUSIONS}

The species pool and propagule source ultimately limit species richness and diversity at a variety of scales, and hydrochory is an efficient vector for linking local plant communities to the regional species pool along free-flowing rivers. The seed shadows of multiple species that are transported by wind and water through time form the template from which new communities are formed and existing communities can be enriched. We found that in the colonization phase of community establishment, propagule source was more important than site conditions in determining species richness of colonizers. However, our results suggest that through time the role of local environmental conditions such as light availability, soil moisture, and fluvial processes (e.g., scour and deposition) become increasingly important in structuring communities and maintaining species-rich sites. Along the regulated Ume River community assembly is primarily controlled by initial and annual seed supplies from water-dispersed propagules. Along free-flowing rivers hydrochory may replenish sites following disturbance, accelerate establishment, and provide stochastic introductions of species from elsewhere (locally unique species) through long-distance dispersal. Dispersal also plays a very important role in free-flowing systems, but on these systems there is a complex interplay between fluvial processes, physical heterogeneity of sites, site history, local species pools, and stochastic dispersal processes.

Experimental studies suggest that hydrochory is important for the maintenance of plant populations (Staniforth and Cavers 1976, Schneider and Sharitz 1988, Johansson and Nilsson 1993) and communities (Andersson et al. 2000b, Jansson et al. 2005, Merritt and Wohl 2006). Indeed, the ecological, genetic, and evolutionary importance of water dispersal to riparian and aquatic plants and plant community structure has been demonstrated in studies conducted on rivers in biomes throughout the world (Nilsson et al. 2010). Through manipulating the sources of propagules reaching new sites along a free-flowing and a heavily regulated river, this study represents the first large-scale, long-term experimental study in which hydrochory has been compared to other means of dispersal, building upon the findings of Jansson et al. (2005). The current work provides experimental evidence suggesting the importance of water dispersal of plant propagules in colonization dynamics along regulated rivers and suggests that hydrochory plays an important yet complex role in colonization dynamics along freeflowing rivers as well.

This study also highlights the importance of maintaining native species diversity, as the inertia of native communities appears to be strong. The high richness at 
sites along the Vindel River is likely to be selfperpetuating both at local and regional scales due to the maintenance of physical processes that support extant species and the landscape permeability that facilitates the rescue of populations when localized extinctions should occur. This inertia renders such systems resilient to catastrophic events that might occasionally cause local extinctions as well as long-term fluctuations (such as climate change; Renöfält et al. 2007). If riparian vegetation were left intact but propagule sources were fragmented along the Vindel River, it is likely that local populations would maintain species richness as long as the range of physical processes and habitats were maintained as well. However, over multi-decadal timescales or over the course of a single catastrophic event, the probability of rescue would diminish as a function of the degree of fragmentation from the meta-population or metacommunity. Populations of plants that are sensitive to the effects of natural drought cycles, disease, extreme winters, herbivory, human harvest, and fire are certain to suffer mortality and occasional localized extinction. Generalist species that also occur in tributaries or wetlands elsewhere in the landscape might reestablish relatively quickly. Species dispersed well by wind or animals might also recolonize relatively easily, whereas other species may fail to reestablish. The rates and frequency of occurrence of long-dispersal events would certainly diminish. At the population level, some species would likely remain absent from reaches downstream of such an obstruction. Communities would likely shift from species with a variety of traits to communities of well-dispersed, cosmopolitan, generalists (e.g., ruderal species) or they may become dominated by a few competitive species.

Species richness is directly related to the functioning of ecosystems (Naeem et al. 1994). Understanding the factors that control species richness, colonization, extinction, turnover, and species composition along rivers is important as most of the world's rivers are developed and heavily managed by humans (Nilsson et al. 2005). The rate of extinction in freshwater ecosystems is high and increasing, and riverine and aquatic ecosystems are becoming simplified through homogenization of physical processes (Poff et al. 2007) and fragmented by impoundments (Merritt and Wohl 2006, Brown and Chenoweth 2008). Further, given that plant species richness is related to other important ecosystem processes such as productivity, resistance to invasion, habitat and resource heterogeneity, and ecosystem functioning, sustaining the processes that maintain plant species richness has important ecological as well as sociological and economic implications.

Our results suggest that riparian sites that are already species-rich may subsidize new sites with species and may self-regulate species richness over short timescales (five years). Our results also suggest that the fragmentation of river reaches from one another and from their regional species pool could lead to long-term depletion of community richness, likely leading to reduced functioning of these ecosystems over time. Sufficient numbers of rivers are fragmented to varying degrees to provide rich opportunities for large-scale natural experiments such as the one we present here. We encourage continued study of dispersal in a range of settings, over long periods of time, and along rivers with varying degrees of fragmentation to help to identify the consequences of landscape connectivity and fragmentation to dispersal processes, plant diversity, and ecosystem maintenance and functioning.

\section{ACKNOWLEDGMENTS}

The authors acknowledge the laboratory and field support of Tiina Kumpula, Magnus Svedmark, Birgitta Renöfält, Elisabet Carlborg, Åsa Bång, Ursula Zinko, Marcus Åström, and the rest of the Landscape Ecology Group at Umea University. We appreciate Christopher Peltz's assistance with the study area map. This study was supported by a postdoctoral grant from the Swedish Research Council (through C. Nilsson to D. M. Merritt). This manuscript was improved by comments from three anonymous reviewers.

\section{Literature Cited}

Andersson, E., and C. Nilsson. 2002. Temporal variation in the drift of plant litter and propagules in a small boreal river. Freshwater Biology 47:1674-1684.

Andersson, E., C. Nilsson, and M. E. Johansson. 2000a. Effects of river fragmentation on plant dispersal and riparian flora. Regulated Rivers: Research and Management 16:83-89.

Andersson, E., C. Nilsson, and M. E. Johansson. 2000b. Plant dispersal in boreal rivers and its relation to the diversity of riparian flora. Journal of Biogeography 27:1095-1106.

Bakker, C., J. M. Blair, and A. K. Knapp. 2003. Does resource availability, resource heterogeneity or species turnover mediate changes in plant species richness in grazed grasslands? Oecologia 137:385-391.

Bång, A., C. Nilsson, and S. Holm. 2007. The role of tributaries as seed sources to a run-of-river impoundment in northern Sweden: a field experiment. River Research and Applications 23:1049-1057.

Bever, J. D. 2003. Soil community feedback and the coexistence of competitors: conceptual frameworks and empirical tests. New Phytologist 157:465-473.

Boedeltje, G., J. P. Bakker, R. M. Bekker, J. M. Van Groenendael, and M. Soesbergen. 2003. Plant dispersal in a lowland stream in relation to occurrence and three specific life-history traits of the species in the species pool. Journal of Ecology 91:855-866.

Boudell, J. A., and J. C. Stromberg. 2008. Propagule banks: potential contribution to restoration of an impounded and dewatered riparian ecosystem. Wetlands 28:656-665.

Brown, J. H., and A. Kodric-Brown. 1977. Turnover rates in insular biogeography: effect of immigration on extinction. Ecology 58:445-449.

Brown, R. L., and J. Chenoweth. 2008. The effect of Glines Canyon Dam on hydrochorous seed dispersal in the Elwha River. Northwest Science 82:197-209.

Burke, M. J. W., and J. P. Grime. 1996. An experimental study of plant community invasibility. Ecology 77:776-790.

Chambert, S., and C. S. James. 2009. Sorting of seeds by hydrochory. River Research and Applications 25:48-61.

Colwell, R. K. 2004. EstimateS 7.0: statistical estimation of species richness and shared species from samples. User's guide and application. /http://viceroy.eeb.uconn.edu/ estimates $\rangle$ 
Danvind, M., and C. Nilsson. 1997. Seed floating ability and distribution of alpine plants along a northern Swedish river. Journal of Vegetation Science 8:271-276.

Gilpin, M. E., and J. M. Diamond. 1976. Calculation of immigration and extinction curves from the species-areadistance relation. Proceedings of the National Academy of Sciences USA 73:4130-4134.

Gower, J. C. 1971. A general coefficient of similarity and some of its properties. Biometrics 27:857-871.

Groves, J. H., D. G. Williams, P. Caley, R. H. Norris, and G. Caitcheon. 2009. Modelling of floating seed dispersal in a fluvial environment. River Research and Applications 25: 582-592.

Gurnell, A., J. Goodson, K. Thompson, N. Clifford, and P. Armitage. 2007. The river-bed: a dynamic store for plant propagules? Earth Surface Processes and Landforms 32: $1257-1272$.

Hanski, I., and D. Simberloff. 1997. The metapopulation approach, its history, conceptual domain, and application to conservation. Pages 5-26 in I. A. Hanski and M. E. Gilpin, editors. Metapopulation biology. Academic Press, San Diego, California, USA

Holyoak, M., M. A. Leibold, and R. D. Holt. 2005. Metacommunities: spatial dynamics and ecological communities. University of Chicago Press, Chicago, Illinois, USA.

Huston, M. A. 1999. Local processes and regional patterns: appropriate scales for understanding variation in the diversity of plants and animals. Oikos 86:393-401.

Jansson, R., C. Nilsson, M. Dynesius, and E. Andersson. $2000 a$. Effects of river regulation on riparian vegetation: a comparison of eight boreal rivers. Ecological Applications 10:203-224.

Jansson, R., C. Nilsson, and B. Renöfält. 2000b. Fragmentation of riparian floras in rivers with multiple dams. Ecology 81: 899-903.

Jansson, R., U. Zinko, D. M. Merritt, and C. Nilsson. 2005. Hydrochory increases riparian plant species richness: a comparison between a free-flowing and a regulated river. Journal of Ecology 93:1094-1103

Joe, H., and R. Zhu. 2005. Generalized Poisson distribution: the property of mixture of Poisson and comparison with negative binomial distribution. Biometrical Journal 47:219229.

Johansson, M. E., and C. Nilsson. 1993. Hydrochory, population dynamics and distribution of the clonal aquatic plant Ranunculus lingua. Journal of Ecology 81:81-91.

Johansson, M., C. Nilsson, and E. Nilsson. 1996. Do rivers function as corridors for plant dispersal? Journal of Vegetation Science 7:593-598.

Kalliola, R., J. Salo, M. Puhakka, and M. Rajasilta. 1991. New site formation and colonizing vegetation in primary succession on the western Amazon floodplains. Journal of Ecology 79:877-901.

Legendre, P., and L. Legendre. 1998. Numerical ecology. Second edition. Elsevier, Amsterdam, The Netherlands.

Levine, J. M. 2000. Complex interactions in a streamside plant community. Ecology 81:3431-3444.

Levine, J. M. 2003. A patch modeling approach to the community-level consequences of directional dispersal. Ecology $84: 1215-1224$.

Leyer, I. 2006. Dispersal, diversity and distribution patterns in pioneer vegetation: the role of river-floodplain connectivity. Journal of Vegetation Science 17:407-416.

Littell, R. C., G. A. Milliken, W. W. Stroup, R. D. Wolfinger, and O. Schabenberger. 2006. SAS for mixed models. Second edition. SAS Institute, Cary, North Carolina, USA.

MacArthur, R. H., and E. O. Wilson. 1967. The theory of island biogeography. Princeton University Press, Princeton, New Jersey, USA.
Mahoney, J. M., and S. B. Rood. 1998. Streamflow requirements for cottonwood seedling recruitment: an integrative model. Wetlands 18:634-645.

McCune, B., and D. Keon. 2002. Equations for potential annual direct incident radiation and heat load. Journal of Vegetation Science 13:603-606.

Merritt, D. M., and E. E. Wohl. 2002. Processes governing hydrochory along rivers: hydraulics, hydrology, and dispersal phenology. Ecological Applications 12:1071-1087.

Merritt, D. M., and E. E. Wohl. 2006. Plant dispersal along rivers fragmented by dams. River Research and Applications 22:1-26.

Morrison, L. W. 2003. Plant species persistence and turnover on small Bahamian islands. Oecologia 136:51-62.

Naeem, S., L. J. Thompson, S. P. Lawler, J. H. Lawton, and R. M. Woodfin. 1994. Declining biodiversity can alter the performance of ecosystems. Nature 368:734-737.

Nilsson, C., E. Andersson, D. M. Merritt, and M. E. Johansson. 2002. Differences in riparian flora between riverbanks and river lakeshores explained by dispersal traits. Ecology 83:2878-2887.

Nilsson, C., R. L. Brown, R. Jansson, and D. M. Merritt. 2010 The role of hydrochory in structuring riparian and wetland vegetation. Biological Reviews. [doi: 10.1111/j.1469-185X. 2010.00129.x]

Nilsson, C., A. Ekblad, M. Dynesius, S. Backe, M. Gardfjell, B. Carlberg, S. Hellqvist, and R. Jansson. 1994. A comparison of species richness and traits of riparian plants between a main channel and its tributaries. Journal of Ecology 82:281295.

Nilsson, C., A. Ekblad, M. Gardfjell, and B. Carlberg. 1991a. Long-term effects of river regulation on river margin vegetation. Journal of Applied Ecology 28:963-987.

Nilsson, C., M. Gardfjell, and G. Grelsson. 1991b. Importance of hydrochory in structuring plant communities along rivers. Canadian Journal of Botany 69:2631-2633.

Nilsson, C., and G. Grelsson. 1990. The effects of litter displacement on riverbank vegetation. Canadian Journal of Botany 68:735-741.

Nilsson, C., C. A. Reidy, M. Dynesius, and C. Revenga. 2005. Fragmentation and flow regulation of the world's large river systems. Science 308:405-408.

Poff, N. L., J. D. Olden, D. M. Merritt, and D. M. Pepin. 2007. Homogenization of regional river dynamics by dams and global biodiversity implications. Proceedings of the National Academy of Sciences USA 104:5732-5737.

Renöfält, B. M., D. M. Merritt, and C. Nilsson. 2007. Connecting variation in vegetation and stream flow: the role of geomorphic context in vegetation response to large floods along boreal rivers. Journal of Applied Ecology 44:147-157.

Ricklefs, R. E. 1987. Community diversity: relative roles of local and regional processes. Science 235:167-171.

Ricklefs, R. E. 2004. A comprehensive framework for global patterns in biodiversity. Ecology Letters 7:1-15.

Romell, L. G. 1938. Växternas spridningsmöjligheter. Pages 279-488 in C. Skottsberg, editor. Växternas liv IV. Nordisk Familjeboks Förlag AB, Stockholm, Sweden.

Schneider, R. L., and R. R. Sharitz. 1988. Hydrochory and regeneration in a bald cypress-water tupelo swamp forest. Ecology 69:1055-1063.

Shmida, A., and M. V. Wilson. 1985. Biological determinants of species diversity. Journal of Biogeography 12:1-20.

SMHI [Swedish Meteorological and Hydrological Institute]. 1979. Streamflow records of Sweden. Swedish Meteorological and Hydrological Institute, Stockholm, Sweden.

Srivastava, D. S. 1999. Using local-regional richness plots to test for species saturation: pitfalls and potentials. Journal of Animal Ecology 68:1-16.

Staniforth, R. J., and P. B. Cavers. 1976. An experimental study of water dispersal in Polygonum spp. Canadian Journal of Botany 54:2587-2596. 
Starzomski, B. M., R. L. Parker, and D. S. Srivastava. 2008. On the relationship between regional and local species richness: a test of saturation theory. Ecology 89:1921-1930.

Turnbull, L. A., M. J. Crawley, and M. Rees. 2000. Are plant populations seed-limited? A review of seed sowing experiments. Oikos 88:225-238.

van der Heijden, M. G. A., R. D. Bardgett, and N. M. van Straalen. 2008. The unseen majority: soil microbes as drivers of plant diversity and productivity in terrestrial ecosystems. Ecology Letters 11:296-310.

Vogt, K., L. Rasran, and K. Jensen. 2004. Water-borne seed transport and seed deposition during flooding in a small river-valley in northern Germany. Flora 199:377-388.

Vogt, K., L. Rasran, and K. Jensen. 2006. Seed deposition in drift lines during an extreme flooding event: evidence for hydrochorous dispersal? Basic and Applied Ecology 7:422432

Vogt, K., L. Rasran, and K. Jensen. 2007. Seed deposition in drift lines: opportunity or hazard for species establishment? Aquatic Botany 86:385-392.

With, K. A. 2002. The landscape ecology of invasive spread. Conservation Biology 16:1192-1203.

Xiong, S. J., M. E. Johansson, F. M. R. Hughes, A. Hayes, K. S. Richards, and C. Nilsson. 2003. Interactive effects of soil moisture, vegetation canopy, plant litter and seed addition on plant diversity in a wetland community. Journal of Ecology 91:976-986.

Zobel, M. 1997. The relative role of species pools in determining plant species richness: an alternative explanation of species coexistence? Trends in Ecology and Evolution 12: $266-269$.

\section{APPENDIX A}

Results of repeated-measures generalized linear models and general linear models on the effects of river reach and treatment and their interaction (Ecological Archives M080-021-A1).

\section{APPENDIX B}

Results of multiple comparison tests in cases when repeated-measures generalized or general linear models indicated a significant reach type or treatment effect (Ecological Archives M080-021-A2).

\section{APPENDIX C}

Generalized linear models of mean plot-scale species richness as a function of treatment and environmental covariables (Ecological Archives M080-021-A3).

\section{APPENDIX D}

Generalized linear models of cumulative site-scale species richness as a function of treatment, insolation, number of upstream tributaries, and reservoir area for impounded reaches (Ecological Archives M080-021-A4). 